\title{
Liver Acinus Zone 1
}

National Cancer Institute

\section{Source}

National Cancer Institute. Liver Acinus Zone 1. NCI Thesaurus. Code C32993.

An area of hepatocytes that are closest to an arteriole. Because of their close proximity to oxygenated blood, the cells in this zone carry out oxidative processes such as betaoxidation, cholesterol synthesis and gluconeogenesis. 